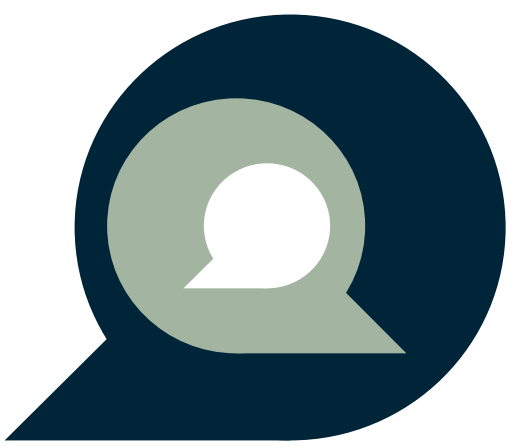




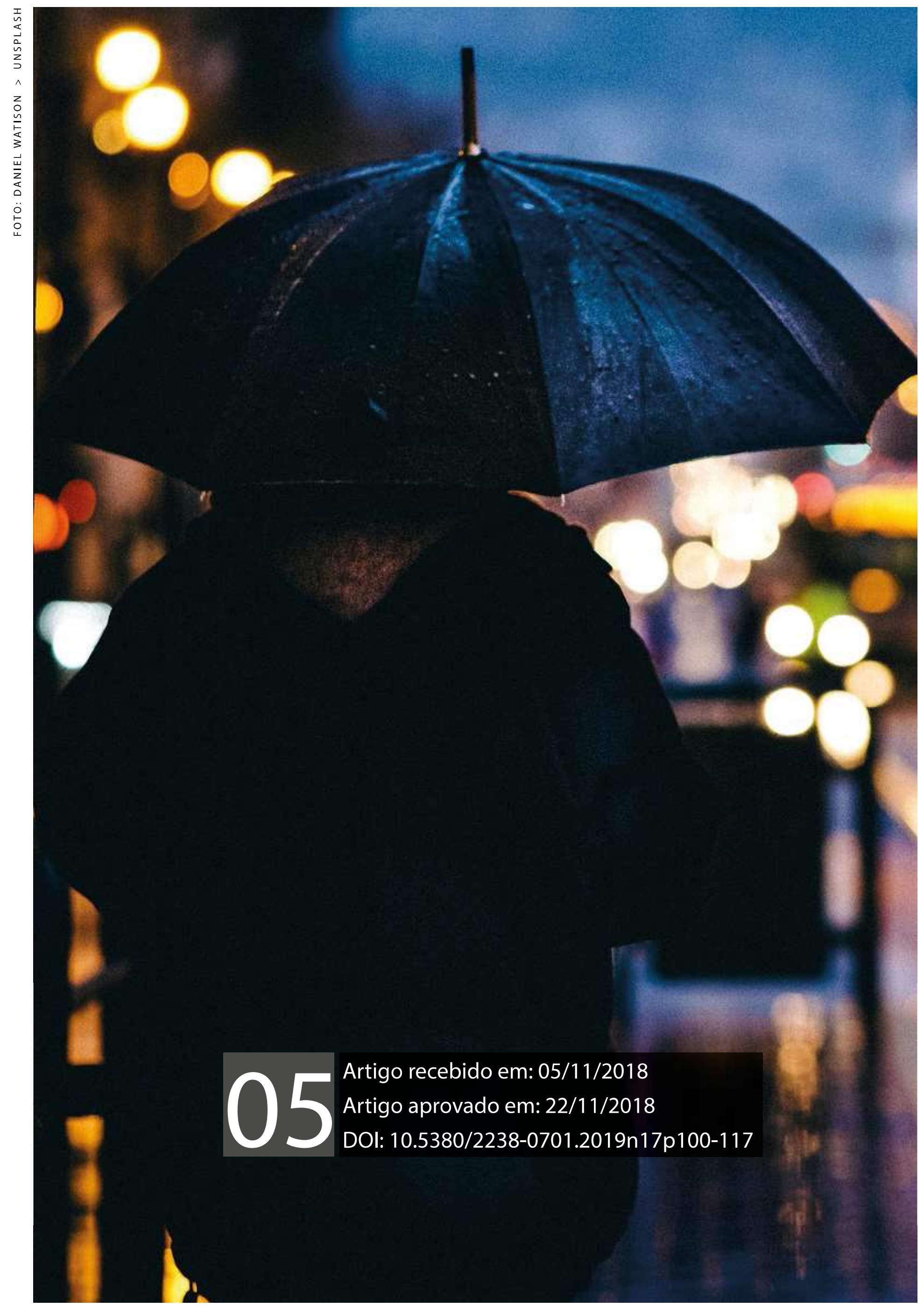


Tempo, depressão e sociedade deadline: um diálogo entre Han, Rosa e Bauman. 


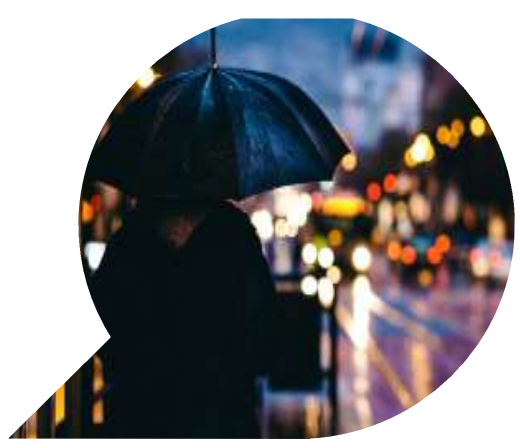

\section{Tempo, depressão e sociedade deadline: um diálogo entre Han, Rosa e Bauman}

Tiempo, depresión y sociedad deadline: un diálogo entre Han, Rosa y Bauman

Time, depression and deadline society: a dialogue between
Han, Rosa and Bauman

RODOLFO RORATO LONDERO ${ }^{1}$

SAMILO TAKARA ${ }^{2}$

Resumo: O objetivo deste ensaio é refletir sobre a percepção do tempo em um contexto marcado predominantemente pelo excesso de informações, tomando como referência as obras de três autores importantes: $\mathrm{O}$ aroma do tempo de Byung-Chul Han; Alienação e aceleração de Hartmut Rosa; e Vida para consumo de Zygmunt Bauman. Percebe-se que, para os três autores, o tempo é atualmente experimentado como momentos ou oportunidades desconexas, incapazes de estabelecer relações entre si e, portanto, formarem uma narrativa. Denominado de "tempo de pontos" (Han) ou "tempo pontilhista" (Bauman), busca-se também com-

1 Doutor em Estudos Literários pela Universidade Federal de Santa Maria. Professor do Departamento de Comunicação e do Programa de Pós-Graduação em Comunicação da Universidade Estadual de Londrina.

2 Doutor em Educação pela Universidade Estadual de Maringá. Professor do Departamento de Educação da Universidade Federal de Rondônia 
preender as consequências de experimentar essa forma de tempo, sinalizando a depressão como principal efeito. Por fim, propõe-se o conceito de sociedade deadline como uma tentativa de expressar essa relação entre tempo pontilhista, excesso de informações e depressão.

\section{Palavras-chave: Percepção do tempo; Depressão; Byung-Chul Han; Harmut Rosa; Zygmunt Bauman.}

Resumen: El objetivo de este ensayo es reflexionar sobre la percepción del tiempo en un contexto marcado predominantemente por el exceso de informaciones, tomando como referencia las obras de tres autores importantes: El aroma del tiempo, de Byung-Chul Han; Alienación y aceleración, de Hartmut Rosa; y Vida de consumo, de Zygmunt Bauman. Se percibe que, para los tres autores, el tiempo es actualmente experimentado como momentos desconectados, incapaces de establecer relaciones entre sí y, por lo tanto, formar una narrativa. Llamado de "tiempo de puntos" (Han) o "tiempo puntillista" (Bauman), se busca también comprender las consecuencias de experimentar esa forma de tiempo, señalando la depresión como principal efecto. Por último, se propone el concepto de sociedad deadline como un intento de expresar esa relación entre tiempo puntillista, exceso de informaciones y depresión.

Palabras clave: Percepción del tiempo; Depresión; Byung-Chul Han; Harmut Rosa; Zygmunt Bauman.

Abstract: The aim of this essay is to reflect on the perception of time in a context marked predominantly by the excess of information, taking as reference the works of three important authors: The scent of time by Byung-Chul Han; Alienation and acceleration by Hartmut Rosa; and Consuming life by Zygmunt Bauman. According to these three authors, time is currently experienced as disconnected moments incapable of establishing relations between them and, therefore, forming a narrative. This essay also seeks to understand the consequences of experiencing this form of time called "pointtime" (Han) or "pointillist time" (Bauman), signaling depression as the main effect. Finally, we propose the concept of deadline society as an attempt to express this relationship between pointillist time, excess of information and depression. 
Keywords: Perception of time; Depression; Byung-Chul Han; Harmut Rosa; Zygmunt Bauman.

\section{Introdução}

Como ocorre a percepção do tempo em um contexto marcado predominantemente pelo excesso de informações? Para responder essa pergunta, esse ensaio propõe examinar como esse tema está presente nas obras de três importantes interlocutores da contemporaneidade: $\mathrm{O}$ aroma do tempo de Byung-Chul Han; Aceleração e alienação de Hartmut Rosa; e Vida para consumo de Zygmunt Bauman. Buscaremos mostrar que, para os três autores, a atual experiência do tempo é marcada por momentos desconexos, que não estabelecem relações entre si e, portanto, não formam uma narrativa. É por isso que esses autores a denominam de "tempo de pontos" (Han, 2016) ou "tempo pontilhista" (Bauman, 2008), sendo a depressão uma de suas principais consequências.

Visando a organização do ensaio, iremos dividi-lo em três partes, cada uma dedicada a um dos autores mencionados. Por fim, nas considerações finais, proporemos, de modo exploratório, o conceito de sociedade deadline como uma tentativa de expressar essa relação entre tempo pontilhista, excesso de informações e depressão.

\section{“O tempo sem aroma”: Byung-Chul Han}

Em Por favor, feche os olhos, Byung-Chul Han (2016) nos pede para fazer o impossível. Ele fala em fechar os olhos tanto como metáfora quanto como metonímia. Enquanto metonímia, a dificuldade em fechar os olhos é evidente: somos constantemente convocados a acompanhar imagens cada vez mais rápidas, em um desfile (ou em uma timeline) sem fim. Se o principal inimigo do capitalismo 24/7 - 24 horas por dia, 7 dias por semana - é o sono (CRARY, 2014), então fechar os olhos é o sinal da proximidade do inimigo. Por sua vez, enquanto metáfora, fechar os olhos significa conclusão: 
As imagens digitais atuais carecem de silêncio e, portanto, de música, e inclusive de aroma. O aroma também é uma forma de conclusão. As imagens sem silêncio não falam ou narram, mas fazem ruído. Diante dessas imagens que "zunem", não podemos fechar os olhos. Fechar os olhos é ensaiar uma conclusão. Hoje a percepção é incapaz de conclusão, pois faz zapping por uma rede digital sem fim. A mudança rápida de imagens impossibilita fechar os olhos, pois isto pressupõe uma espera contemplativa. As imagens estão constituídas hoje de tal maneira que não é possível fechar os olhos. Entre elas e os olhos se produz um contato imediato, que não admite nenhuma distância contemplativa. A coação a permanente vigilância e visibilidade dificulta fechar os olhos. A transparência é a expressão da hipervigília e da hipervisibilidade ${ }^{3}$ (HAN, 2016, p. 8-9).

A impossibilidade de concluir, de fechar os olhos, é resultado do fim da narrativa. Benjamin (1987a) é um dos primeiros a perceber como a informação substituiu a narrativa. Enquanto a narrativa nos conta uma experiência com começo, meio e fim, ou seja, de forma encadeada, portanto, plena de sentido, a informação nos apresenta apenas o fato, sem começo, sem fim, portanto, sem sentido. A informação não consegue oferecer um começo (um motivo) e muito menos um fim (um sentido). Enquanto os mitos conseguem oferecer um motivo e um sentido para um acidente de avião ("vontade de Deus", por exemplo), uma notícia apenas informa: "127 pessoas morreram em um acidente de avião".

Do ponto de vista da percepção, Han (2016) mostra que, no caso das imagens digitais, não conseguimos oferecer uma forma acabada para o que vemos: as imagens sempre chamam mais imagens. A contemplação torna-se impossível não apenas por causa dessa "mudança rápida de imagens", mas também porque somente contemplamos aquilo que está acabado. Como contemplar a pintura ainda sendo pintada? Neste caso, o que nos resta é esperar. Entretanto, no caso das redes digitais, passamos para a próxima imagem porque as próprias imagens estão inacabadas: por exemplo, uma selfie sempre pede por sua próxima atualização (ao contrário de um retrato, que consideramos acabado). Ainda seguindo o raciocínio da citação acima, Han (2016) fala que, entre as imagens digitais e os olhos, se produz um "contato imediato", o que também impede a contemplação. A expressão "contato imediato" exprime adequadamente o fenômeno, pois entre a imagem técnica e

3 Esta e as demais citações em língua estrangeira foram livremente traduzidas por nós. 
o olho não há mediação (i-mediato). Ao contrário das imagens arcaicas, que serviam como mediação para o mundo, as imagens técnicas se apresentam como o próprio mundo (FLUSSER, 2011). Neste sentido, as imagens arcaicas permitiam contemplar o mundo de forma acabada: os caçadores de Lascaux contemplavam a narrativa da caçada, seu começo, meio e fim. Entretanto, no caso das imagens técnicas, o mundo é apresentado sem mediação, sem narrativa, portanto, inacabado: o mundo das notícias está sempre acontecendo.

Ao falar do "tempo sem aroma", marcado por "picos de atualidade", Han (2016) retoma uma analogia já apresentada por outros autores Flusser (2007), por exemplo -, apresentando o tempo mítico enquanto imagem (circularidade) e o tempo histórico enquanto linha (progresso). A novidade é a analogia por ele apresentada para se referir ao tempo atual: o ponto (ao invés da "superfície" de Flusser). Vejamos:

Na verdade, a informação apresenta um novo paradigma. Em seu interior há uma outra temporalidade muito diferente. É uma manifestação do tempo atomizado, de um tempo de pontos (Punkt-Zeit).

Entre os pontos se abre necessariamente um vazio, um intervalo vazio, onde nada acontece, não se produz sensação alguma. O tempo mítico e histórico, ao contrário, não deixam nada vazio, visto que a imagem e a linha não possuem nenhum intervalo. [Eles] constituem uma continuidade narrativa. Somente os pontos deixam um intervalo vazio. Os intervalos, onde nada acontece, causam tédio. Ou se apresentam como uma ameaça, visto que onde nada acontece, onde a intencionalidade resulta em nada, está a morte. Deste modo, o tempo de pontos sente o impulso de suprimir ou cortar os intervalos vazios. Para evitar que [esses intervalos] demorem demasiadamente, buscamos sensações cada vez mais rápidas. Isto produz uma aceleração cada vez mais histérica da sucessão de acontecimentos ou fragmentos, que se estendem a todos os âmbitos da vida. A falta de tensão narrativa e o tempo atomizado fazem com que não possamos manter a atenção de maneira duradoura. Isto faz com que a percepção se abasteça constantemente de novidades e radicalismos. O tempo de pontos não permite nenhuma espera contemplativa (HAN, 2015a, p. 36-37; grifos do autor).

A falta de continuidade entre os pontos abre um vazio. Em outras palavras: a falta de uma narrativa, de um sentido, capaz de oferecer coe- 
rência para nossas variadas experiências e acontecimentos mundanos, nos faz contemplar o abismo da morte. É por isso que experimentamos a vertigem do abismo como ameaça e para evitar essa ameaça, "buscamos sensações cada vez mais rápidas", como diz o autor.

Do ponto de vista da percepção, o tempo atomizado nos impossibilita de manter a atenção duradoura. Este é um problema já referido por nós (LONDERO, 2017), mas precisamos relacioná-lo ao problema apresentado logo acima. Sabemos, segundo Benjamin (1987b), que a atenção/contemplação é o movimento do sujeito para o objeto, e que a diversão/fruição é o movimento do objeto para o sujeito. Apesar de Benjamin não endossar os argumentos a seguir, principalmente porque estava interessado em apresentar o cinema como nova arte, é preciso destacar como a diversão/fruição é a afirmação do sujeito por meio do objeto. Morin (1977) explicar isto ao mostrar os processos de identificação e projeção levados a cabo pelo cinema. Atualmente conseguiríamos explicar isto de um jeito mais fácil, graças às redes digitais: somos aquilo que curtimos, que compartilhamos, que comentamos, enfim, somos esses muitos objetos que nos constituem. Por outro lado, a atenção/contemplação é a negação do sujeito por meio do objeto: ao dirigir sua atenção para o objeto, o sujeito nele se perde. Se precisamos lembrar do sentido etimológico da palavra "experiência" ("fora do limite conhecido"), então é porque não podemos falar em experiência quando o sujeito não se perde; e existem muitas formas de se perder, todas elas distantes das redes digitais: nos braços da pessoa amada, nos traços de uma pintura, no êxtase da dança.

\section{“As pegadas externas da memória”: Hartmut Rosa}

Ainda que Han (2015a, p. 25) reconheça como "um pouco ingênua" sua leitura, o que Hartmut Rosa (2016) chama de padrão curto/curto, em referência a um tempo breve tanto na experiência quanto na memória, vai ao encontro de alguns questionamentos levantados pelo filósofo germano-coreano. Não por acaso, para exemplificar o padrão curto/ curto, Rosa (2016) cita a televisão: quando assistimos a um programa que realmente nos entretém, não sentimos o tempo passar (experiência temporal breve) e também não nos recordamos dessa experiência como algo marcante, como algo que deixa "pegadas de memória" (memória 
temporal breve). Nas palavras de Rosa, "o tempo passa rapidamente na experiência, mas se encolhe na memória" (ROSA, 2016, p. 168). Rosa apresenta duas explicações para esse padrão curto/curto que discutiremos a seguir.

A primeira explicação diz respeito à própria experiência de assistir televisão: Rosa (2016) a define como "des-sensualizada", ou seja, ela não envolve todos os sentidos de forma integrada. Podemos então estabelecer uma relação entre sinestesia e qualidade da experiência (isto se realmente concordarmos que uma experiência que marca nossa memória, que deixa "pegadas", é uma experiência de qualidade). Para quem estuda a fenomenologia da percepção, essa relação não é surpreendente, pois “a percepção sinestésica é a regra, e, se não percebemos isso, é porque o saber científico desloca a experiência e porque desaprendemos a ver, a ouvir e, em geral, a sentir" (MERLEAU-PONTY, 2011, p. 308). Mais que a crítica ao saber científico (importante para o projeto da fenomenologia), o importante é compreender as mídias audiovisuais como antipedagógica aos sentidos, ou seja, como responsáveis por desaprendermos a sentir o mundo. Ao estimularem apenas um ou dois sentidos, muitas vezes de forma não enriquecedora (por exemplo, a trilha sonora como redundância da imagem ou vice-versa), as mídias audiovisuais transformam a regra da percepção sinestésica em exceção.

$\mathrm{Na}$ verdade, podemos até questionar se realmente os sentidos são estimulados ou se estamos diante de um processo de "abstração estética" (HAUG, 1997): neste último caso, ignoramos os sentidos e recebemos apenas informação. Este é o entendimento de Virilio quando diz que, diante da tela do computador, "o que se oferece é justamente informação, mas não sensação” (VIRILIO, 2015, p. 53). Dificilmente uma informação produz "pegadas de memória", o que confirma o diagnóstico de Benjamin (1987a) sobre estarmos ricos de informação, mas pobres de experiência. Como afirma Rosa, "esta tendência a apagar (ou não deixar) pegadas na memória é bastante útil em uma sociedade de aceleração na qual a experiência é, em sua maior parte, anacrônica e inútil, e onde é preciso estar preparado para o novo e imprevisto" (ROSA, 2016, p. 169). Se atualmente vivemos no automático, como se costuma dizer, é porque perceber e experimentar o mundo possuem pouca serventia. Neste sentido, as palavras de Merleau-Ponty ganharam uma atualidade que nem ele poderia imaginar: "esse mundo [da percepção] é em grande medida ignorado por nós enquanto permanecemos numa postura prá- 
tica ou utilitária" (MERLEAU-PONTY, 2004, p. 1). O alvo original de Merleau-Ponty era o pensamento cartesiano, mas podemos redirecioná-lo para o mundo construído em torno desse pensamento: a tela do computador é o cogito cartesiano, capaz de filtrar a sensação e fornecer apenas a informação.

A segunda explicação para o padrão curto/curto diz respeito à recepção: como os conteúdos apresentados não correspondem aos nossos estados ou experiências, nós os recebemos como "episódios isolados", descontextualizados (o "tempo de pontos" de Han). Nas palavras de Rosa, "dado que não possuem relevância para nossas vidas, ou para nossas identidades em sua totalidade, e dado que não agregam em nada nossas experiências passadas, tendemos a esquecer estes episódios de imediato" (ROSA, 2016, p. 169). Neste ponto, as pesquisas em publicidade podem contribuir bastante, até porque os anúncios e spots sempre apontaram para um padrão curto/curto. Ao pesquisar a publicidade televisiva, Krugman (2002) mostra como a repetição é necessária, pois o conteúdo veiculado pelos anúncios é de baixo envolvimento. Entretanto, mesmo a repetição não é suficiente caso não venha acompanhada de uma experiência de satisfação decorrente do consumo do produto anunciado. De fato, a publicidade funciona justamente por causa dessa relação constante e intercalada entre repetição e satisfação. Esta relação se configura como um padrão curto/curto: satisfação rápida e lembrança efêmera. Portanto, as várias repetições são tomadas como "episódios isolados", lembrando ao consumidor da experiência satisfatória, mas pouco marcante. Neste sentido, podemos dizer que, nos casos de compra repetida, é como se o consumidor experimentasse o produto sempre "pela primeira vez", pois como experiências passadas podem reverberar aqui se nenhuma delas foi marcante? Como já dizia Benjamin (1989), as mercadorias (e os consumidores) vivem um "eterno retorno do novo".

Interpretando o comentário de Benjamin sobre os souvenires, Rosa afirma que eles "não possuem poder para evocar algo em nós, porque são pegadas externas de vivências que agora nos resultam sem sentido" (ROSA, 2016, p. 171). Esta afirmação também cabe para a publicidade. $\mathrm{Na}$ verdade, mais acima havíamos falado em "experiência satisfatória", mas o correto seria dizer "vivência satisfatória", pois, como pudemos perceber, a publicidade e grande parte do consumo não são capazes de produzir experiências, apenas vivências. Ou seja, a sociedade apresenta várias oportunidades de viver coisas novas, mas poucas delas resultam 
em "experiências inesquecíveis", como se costuma dizer. Diante deste cenário, ainda que não tenham poder para evocar algo, os anúncios publicitários, enquanto "pegadas externas da memória", estão constantemente nos dizendo o que realmente tem sentido, visto que estamos carentes de experiências capazes de tornar nossas vidas significativas. Nas palavras de Rosa,

Cada vez mais, nos envolvemos em atividades e contextos que estão rigorosamente isolados uns dos outros. Deste modo, poderíamos ir à academia, depois ao parque de diversão, e depois a um restaurante e a um cinema, visitar o zoológico, assistir a uma conferência, a uma reunião de negócios, parar em um supermercado, etc. Todas estas atividades se traduzem em episódios isolados de ação e experiência que não se relacionam entre si de maneira integrada e nem significativa. Ao final, apenas percebemos que estamos aí (ROSA, 2016, p. 170).

Apresentando diagnóstico semelhante, Jameson (1996) classifica a subjetividade pós-moderna como esquizofrênica. Incapaz de qualquer ligação entre passado e presente ou qualquer projeção entre presente e futuro, o esquizofrênico simplesmente está aí. Ele não saberá responder como chegou onde está e nem dizer para onde vai. Uma metáfora perfeita para nossa atual situação.

\section{“O serial killer das oportunidades": Zygmunt Bauman}

Diante do quadro apresentado acima, não é surpresa perceber que, em Vida para consumo, Zygmunt Bauman (2008) discute o problema do consumo relacionando-o à percepção do tempo e ao excesso de informação. Ao contrário do consumo de bens duráveis como ocorria na modernidade sólida, o consumo na atual modernidade líquida tornou-se imediato, em busca das demandas de um desejo sempre estimulado, mas jamais satisfeito. Como ele próprio diz, ao invés de adquirir e acumular, agora visamos descartar e substituir. Do mesmo modo que Han (2015a), mas apresentando uma fonte omitida pelo filósofo germano-coreano, Bauman (2008) nos fala em três formas do tempo: o tempo cíclico (pré-modernidade), o tempo linear (modernidade sólida) e o tempo pontilhista (modernidade líquida). O conceito de tempo 
pontilhista (derivado de ponto e da técnica de pintura de mesmo nome) é emprestado de Michel Maffesoli (2003) para explicar porque o atual consumo tornou-se imediato. Enquanto o consumo de bens duráveis é sustentado pelo tempo linear, pois ele implica em noção de futuro, logo, em preocupação com segurança, conforto e estabilidade, o consumo imediato é baseado no tempo pontilhista, pois há aqui um universo de oportunidades, de pontos, que devemos aproveitar antes que desapareçam. Esses pontos não estabelecem relações entre si, eles não são ligados por uma linha, por uma narrativa. Um ponto: viagem de férias. Mais um ponto: carro novo. Mais um ponto: promoção de cargo. E assim uma vida inteira é contada, ou melhor, detalhada ponto a ponto. Isto nos leva ao seguinte problema, assim relatado por Bauman:

É exatamente por essas razões que a vida "agorista" [de agora] tende a ser "apressada". A oportunidade que cada ponto pode conter vai segui-lo até o túmulo; para aquela oportunidade única não haverá "segunda chance". Cada ponto pode ter sido vivido como um começo total e verdadeiramente novo, mas se não houve um rápido e determinado estímulo à ação instantânea, a cortina pode ter caído logo após o começo do ato, com pouca coisa acontecendo no intervalo. A demora é o serial killer das oportunidades (BAUMAN, 2008, p. 50).

Trata-se sempre de "um começo total e verdadeiramente novo", como se a vida imitasse a arte de um vanguardista enlouquecido (afinal, a vanguarda modernista também não se liquefez?). Este novo começo está disponível apenas para os apressados, nada restando para os demorados, ou melhor, para aqueles que vivem ou tentam viver em seu próprio tempo (voltaremos a falar deles).

Após abordar o problema do tempo pontilhista, Bauman (2008) apresenta outro problema correlato: o excesso de informação. Se temos tantas oportunidades para explorar, mas sabemos que mesmo os mais apressados jamais conseguirão explorar todas elas, então a informação torna-se importante, pois é ela - na forma de publicidade, marketing e hypes (Bauman os chama de "produtos da indústria de relações públicas") - quem vai nos guiar nessa enxurrada de oportunidades. Entretanto, como sabemos, o excesso de informação remove a linha divisória entre mensagem importante e ruído de fundo. Bauman (2008) vai bus- 
car em Georg Simmel as consequências desse cenário, em sua análise da "atitude blasé" dos habitantes das grandes metrópoles: "[Os objetos] se mostram à pessoa blasé num tom uniformemente cinza e monótono; nenhum objeto tem preferência sobre qualquer outro" (SIMMEL apud BAUMAN, 2008, p. 57). Ou seja, como já não é mais possível saber o que realmente importa, somente nos resta fazer tábula rasa de todas as coisas. Contudo, a conclusão mais interessante é a seguinte:

Um fenômeno cada vez mais destacado, muito semelhante ao que foi descoberto e analisado por Simmel sob o nome de "atitude blasé", [...] é discutido hoje em dia sob o nome de "melancolia". (...) Na versão de Rolland Munro, o conceito de "melancolia" em seu uso atual "representa não tanto um estado de indecisão, uma hesitação entre seguir um ou outro caminho, mas um recuo em relação às próprias divisões". Ele representa um "desenredamento" em relação a "estar atado a qualquer coisa específica". Ser "melancólico" é "sentir a infinidade da conexão, mas não estar engatado em coisa alguma". Em suma, "melancolia" se refere a "uma forma sem conteúdo, uma recusa a saber só isso ou só aquilo" (BAUMAN, 2008, p. 57-58; grifos do autor).

Se os depressivos são os "remanescentes dos antigos melancólicos" (KEHL, 2015, p. 16), então temos aqui uma conjunção reveladora. Primeiramente, para complementar a hipótese de Bauman, precisamos ressaltar a relação entre depressão e tempo pontilhista, como faz Kehl ao dizer o seguinte:

Nada causa tanto escândalo, em nosso tempo, quanto o tempo vazio. $\hat{E}$ preciso "aproveitar" o tempo, fazer render a vida, sem preguiça e sem descanso. A esse imperativo, como veremos, o depressivo resiste com sua lentidão, seu mergulho angustiado e angustiante em um tempo estagnado, que lhe parece não passar. Ainda que eles não saibam disso, a inadaptação dos depressivos em relação às formas contemporâneas de aproveitar o tempo pode ser reveladora da memória recalcada de outra temporalidade, própria do "tempo em que o tempo não contava" (KEHL, 2015, p. 125; grifo da autora).

A depressão é o verdadeiro serial killer das oportunidades. Como sabe que jamais terá o tempo necessário para suas escolhas, ou seja, ja- 
mais terá o seu próprio tempo, o depressivo decide recuar e não fazer nenhuma escolha. Percebam que não se trata do paradoxo da escolha de Schwartz (2007), pois o que causa paralisia neste caso é a possibilidade de fazer a escolha errada diante de tantas opções. Para o depressivo, nem mesmo essa possibilidade existe, pois ele decide não escolher. Dizemos que ele decide, pois isto nos faz compreender sua resistência: "o depressivo quer gozar, mas à sua maneira” (KEHL, 2015, p. 18). É somente assim que ele resgata essa memória recalcada de quando o tempo não contava.

No outro extremo da "evolução (pós-)humana" (LONDERO, 2017), temos a atitude multitarefa, provavelmente o oposto da "atitude blasé" e seus derivados contemporâneos: ao invés de nenhuma preferência, tenta-se priorizar o máximo de oportunidades. Como diz Gitlin, trata-se "de esticar o tempo, de transformar sequência em quase simultaneidade" (GITLIN, 2003, p. 145). Ao invés de pular de ponto em ponto, da forma mais rápida, tenta-se abraçar todos os pontos ao mesmo tempo. Se a depressão é o serial killer das oportunidades, a multitarefa é o vício. Entretanto, ao perceberem o estrago do vício, alguns viciados se revoltam. Daí porque a multitarefa é o caminho mais curto para a depressão: abraçar todas as oportunidades ao mesmo tempo é chegar à conclusão que nenhuma realmente importa. Como acredita Gitlin, em algum momento "a aceleração vai se chocar contra barreiras da natureza ou da psique” (GITLIN, 2003, p. 155. Por enquanto, ela “apenas” está produzindo depressivos e viciados em drogas estimulantes.

\section{Fim da linha}

No ano de 2013, a jornalista japonesa Miwa Sado morreu por ataque cardíaco após acumular um saldo de 159 horas extras ao longo de um mês. Como diz a notícia, "Miwa era repórter da NHK e foi encontrada morta sozinha, em sua cama, com um aparelho celular nas mãos"4. Parece emblemático (para não dizer agourento) que ela tenha morrido com o celular nas mãos. De fato, o caso em geral é coberto de sinais reveladores de nossa situação, desde a causa da morte até a pressão para

4 Disponível em: <http://economia.estadao.com.br/noticias/geral,jornalista-morre-apos-159-horas-extras-no-japao,70002030735>. Acesso em: 02 abr. 2018. 
cumprir com os deadlines. Começaremos por este último.

A expressão "deadline" serviria muito bem para denominar nossa sociedade, pois ela expressa tanto a forma como atualmente lidamos com o tempo - desde o tempo do trabalho (marcado não mais por uma carga horária pré-determinada, mas por prazos e metas a cumprir) até o tempo de lazer (marcado antes por um tempo ocioso que agora buscamos preencher com compromissos e passatempos) - quanto as consequências desta forma imprudente de lidar com o tempo, resultando literalmente no cruzamento da "linha da morte", como ocorreu com a jornalista da NHK. Devemos imaginar o sofrimento da jornalista em seu último ano de vida, quando "raramente folgava durante os finais de semana e trabalhava até a meia-noite todos os dias"5. Esse sofrimento certamente ilustra o que podemos chamar de tempo deadline, tornando mais precisa a definição de Han (2015a) ao falar em "tempo sem aroma". Ainda que ela dormisse e acordasse todos os dias (com certeza de forma precária), não era o tempo natural que regulava sua vida. Sua vida era orientada por prazos que se sucediam um após outro, sem jamais estabelecerem relações entre si. Como já vimos, trata-se de "pontos" isolados, incapazes de formarem em conjunto uma narrativa, pois o que haveria para contar de uma vida assim? As narrativas míticas nos ensinam que, após o cumprimento de uma tarefa, o herói é recompensado de alguma forma, sendo este o momento de conclusão, ou seja, de descanso. Entretanto, como isto seria possível em um tempo 24/7? É interessante perceber que tanto o tempo mítico quanto o tempo 24/7 apontam para o infinito, mas de modos bem diferentes: enquanto o primeiro é cíclico (o "eterno retorno" da tarefa e do descanso), o segundo é repetição sem fim, ou seja, sem descanso (o inferno de Sísifo). A alternância entre tarefa e descanso é importante para impor ritmo à vida; sem ela, o tempo torna-se uma "linha da morte", como a dos aparelhos que medem os batimentos cardíacos de um corpo sem vida.

Esta última referência nos leva à causa da morte da jornalista da NHK: ataque cardíaco. Já é de amplo conhecimento a relação entre ritmo circadiano (o chamado "relógio biológico") e vida saudável em geral. É provado cientificamente que a vida acompanha o tempo natural, ou seja, o tempo do nascimento e do pôr do sol (com exceção das espécies abissais). Em Sociedade do cansaço, ao se contrapor ao paradig-

5 Disponível em: <http://economia.estadao.com.br/noticias/geral,jornalista-morre-apos-159-horas-extras-no-japao,70002030735>. Acesso em: 02 abr. 2018. 
ma imunológico como explicação do nosso horizonte patológico, Han (2015b) propõe a expressão "enfarto psíquico" para denominar as novas enfermidades. A expressão é bastante apropriada, pois o enfarto revela a tentativa desesperada do corpo descansar quando sobrecarregado por um tempo com prazos e metas sem fim, ou seja, um tempo deadline. Entretanto, ao contrário do enfarto da jornalista (apesar dele não excluir o que diremos a seguir), sabemos que o enfarto mencionado por Han é um "enfarto psíquico", traduzido a partir de doenças como depressão, síndrome de burnout, transtornos de ansiedade, etc. Se tomarmos a depressão como exemplo, então mais uma vez a expressão é apropriada, pois o depressivo é aquele que vive e tenta viver em um "tempo estagnado" (KEHL, 2015, p. 17). Em uma sociedade 24/7, viver em um tempo estagnado é morrer socialmente, pois não se consegue acompanhar as expectativas, os deadlines, desse mundo acelerado. Daí Kehl (2015) dizer que a depressão esconde um saber perigoso para a sociedade $24 / 7$, dado que ela propõe uma outra forma de experimentar o tempo. Vejamos o caso da trainee da agência de publicidade Dentsu: Matsuri Takahashi cometeu suicídio devido ao excesso de trabalho. O suicídio dos depressivos é a confirmação da morte social, da incapacidade de a sociedade aceitar uma forma de viver o tempo que não seja por meio de deadlines. A notícia que relata a morte de Takahashi termina citando um famoso manual da agência: "Jamais desista de uma tarefa até que atinja seu objetivo, mesmo que precise morrer tentando"6. A verdade é que estamos mortos desde o momento em que aceitamos viver assim.

\section{REFERÊNCIAS}

BAUMAN, Zygmunt. Vida para consumo: a transformação das pessoas em mercadoria. Rio de Janeiro: Jorge Zahar, 2008.

BENJAMIN, Walter. Charles Baudelaire, um lírico no auge do capitalismo. São Paulo: Brasiliense, 1989.

. O narrador: considerações sobre a obra de Nikolai Leskov. In: Magia e técnica, arte e política: ensaios sobre literatura e história da cultura. São Paulo: Brasiliense, 1987a.

6 Disponível em: <http://www1.folha.uol.com.br/mercado/2016/12/1845766-suicidio-por-excesso-de-trabalho-leva-a-renuncia-de-empresario-japones.shtml>. Acesso em: 02 abr. 2018. 
A obra de arte na era de sua reprodutibilidade técnica. In: Magia e técnica, arte e política: ensaios sobre literatura e história da cultura. São Paulo: Brasiliense, 1987b.

CRARY, Jonathan. 24/7: capitalismo tardio e os fins do sono. São Paulo: Cosac Naify, 2014.

FLUSSER, Vilém. Filosofia da caixa preta: ensaios para uma futura filosofia da fotografia. São Paulo: Annablume, 2011.

O mundo codificado: por uma filosofia do design e da comunicação. São Paulo: Cosac Naify, 2007.

GITLIN, Todd. Mídias sem limite: como a torrente de imagens e sons domina nossas vidas. Rio de Janeiro: Civilização Brasileira, 2003.

HAN, Byung-Chul. Por favor, cierra los ojos: a la búsqueda de otro tiempo diferente. Barcelona: Herder, 2016.

El aroma del tiempo: un ensayo filosófico sobre el arte de demorarse. Barcelona: Herder, 2015a.

Sociedade do cansaço. Petrópolis: Vozes, $2015 b$.

HAUG, Wolfgang Fritz. Crítica da estética da mercadoria. São Paulo: Editora da UNESP, 1997.

JAMESON, Fredric. Pós-modernismo: a lógica cultural do capitalismo tardio. São Paulo: Ática, 1996.

KEHL, Maria Rita. O tempo e o cão: a atualidade das depressões. São Paulo: Boitempo, 2015.

KRUGMAN, Herbert E. Publicidade na televisão - aprendizagem sem envolvimento. In: JONES, John Philip (org.). A publicidade como negócio. São Paulo: Nobel, 2002.

LONDERO, Rodolfo Rorato. "Bem-vindo à próxima fase”: a cultura do 
choque e o fim do tédio. Ação midiática, Curitiba, n. 14, p. 291-305, jul./ dez. 2017.

MAFFESOLI, Michel. O instante eterno: o retorno do trágico nas sociedades pós-moderna. Porto Alegre: Zouk, 2003.

MERLEAU-PONTY, Maurice. Fenomenologia da percepção. São Paulo: Martins Fontes, 2011.

Conversas - 1948. São Paulo: Martins Fontes, 2004.

MORIN, Edgar. Cultura de massas no século XX: o espírito do tempo. Rio de Janeiro: Forense Universitária, 1977.

ROSA, Hartmut. Alienación y aceleración: hacia una teoría crítica de la temporalidad en la modernidad tardía. Madrid: Katz, 2016.

SCHWARTZ, Barry. O paradoxo da escolha: por que mais é menos. São Paulo: Girafa, 2007.

VIRILIO, Paul. Estética da desaparição. Rio de Janeiro: Contraponto, 2015. 